https://doi.org/10.5817/OS2019-2-7

\title{
Српски језик и српска ћирилица
}

Срйски језик и ћирилица gанас: зборник раgова. Главни и одговорни уредник: Емир Кустурица; уредници Милош Ковачевић, Александра Вранеш. Андрићград (Вишеград): Андрићев институт (Библиотека Научни скупови, Одјељења за књижевност, Коло Зборници радова; књига 7), 2017. 134 стр. ISBN 978-99976$-21-20-7$.

Die Frage nach dem Status der Kyrilliza und ihres Anwendungsradius in Bezug auf die serbische Sprache dürfte sich eigentlich gar nicht stellen, denn mit ihr geht nahezu die gesamte diachrone Entwicklung des Serbischen einher. Innerhalb und außerhalb der heutigen Landesgrenzen befinden sich unikale Sprachdenkmäler, die dies eindrucksvoll bezeugen. Heutzutage beobachten wir jedoch, dass die kyrillische Schrift mit der Lateinschrift konkurriert und dass Affinitäten unter den Sprachträgern festgestellt werden können, die bezeugen, dass man dem alltäglichen Gebrauch der Kyrilliza gegenüber anscheinend oftmals indifferent gegenübersteht, was zur Folge hat, dass das traditionelle Alphabet der Serben in der Praxis aus einigen Domänen immer stärker verdrängt und durch das lateinische ersetzt wird. In dem vorliegenden Sammelband werden daher Studien vorgestellt, die den tatsächlichen Usus im Schriftgebrauch auf den Prüfstand stellen und sich mit den Herausforderungen und Möglichkeiten auseinandersetzen, die gegenwärtig mit der serbischen Sprache und ihrer schriftsprachlichen Gestalt interagieren.

Im ersten Text greift Emir Kusturica eine Grundsatzproblematik auf, die mit den Vorbemerkungen eng zusammenhängt, nämlich die politisch motivierte Zerstückelung eines sprachlichen Codes, der in Form der štokavischen Varietäten existiert. Es sollte daher in erster Linie im Interesse des Staates liegen, die serbische Sprache angemessen zu schützen. ${ }^{1}$ Sicher hätte hier auch noch geäußert werden können, wie sich solch ein Schutz auf die Verwendung einer Schriftform auswirken müsste, denn um den ständigen Einfluss der Lateinschrift einzudämmen wird entweder auf politischer Ebene ganz offensichtlich zu wenig getan, oder aber man sieht keinen expliziten Handlungsbedarf, der über die bisherigen Maßnahmen hinausgeht und alle Serben zur ausschließlichen Verwendung der Kyrilliza animiert.

Daran knüpft der Beitrag von Slobodan N. Remetić an, der die sog. Deklaration zur gemeinsamen Sprache (Декларација о зајеgничком језику) kritisch kommentiert, welche im März 2017 von zahlreichen Verfechtern einer gemeinsamen Sprache des -

1 KUSTURICA, E. (ed.): Srpski jezik i ćirilica danas: zbornik radova. Andrićgrad: Andrićev institut, 2017, S. 9-10. 
hier in Anführungszeichen gesetzten - polyzentrischen Sprachraums unterzeichnet wurde und einen gewissen Freiraum in der Bezeichnung der jeweiligen štokavischen Sprachformen einfordert, da sie als eine Varietät betrachtet werden. Remetić gibt einen fundierten Überblick darüber, wie einflussreich politisch motivierte Ansichten im geographischen Raum zwischen Bulgarien und Slowenien nach wie vor sind. ${ }^{2} \mathrm{Im}$ Ergebnis sei die neuartige Deklaration also nichts Neues, vielmehr sei es das Ziel, das Serbische noch mehr als bislang zu unterdrücken, insbesondere in Bosnien und Herzegowina und Montenegro, weshalb der Verfasser einen schweren Vorwurf erhebt: Декларисти, gакле, траже gа се оgрекнемо и Вука, из чијеі су језика изникле хрватска, бошњачка и ирноіорска варијанта њеїовоїа, Вуковоїа језика. ${ }^{3}$

Der dritte Artikel von Miloš M. Kovačević thematisiert den Schutz der serbischen Sprache und der Kyrilliza, denn beide seien in einigen Bereichen in einem alarmierend bedrohten Zustand. ${ }^{4}$ Es wird ein Plan aufgestellt, der zahlreiche Vorschläge für eine gesellschaftlich verankerte Verbesserung des Status quo enthält, so dass Kovačević vor allem eine durchgehende und alleinige offizielle Anerkennung für die Kyrilliza einfordert, um so dem massiven Druck der Lateinschrift in der Praxis entgegen zu wirken (Нужно је зато на свим иросторима на којим Срби живе ћириличу сачувати тако што ће бити јеgино службено иичсмо ицјелоїа срйскоїа нароgа). ${ }^{5}$ Auch wenn es ein weitreichender und kostspieliger Schritt wäre, den vielleicht ein Teil der Bevölkerung im Zeitalter der Digitalisierung (die in Serbien zweifelsfrei die ohnehin fortgeschrittene Latinisierung zusätzlich intensiviert) gar nicht nachvollziehen würde, so scheint dies heute wohl doch die Ultima Ratio zu sein, um dem permanenten Schwanken zwischen zwei graphischen Systemen Einhalt zu gewähren und eine klare Positionierung zur Schriftsprache vorzunehmen. So trivial es auch klingen mag, aber sobald man der Lateinschrift ihren jetzigen Status entziehen und sie nicht länger zur Wiedergabe des Serbischen tolerieren würde, wenn dann alle Aufschriften im öffentlichen Raum, alle Textsorten, alle modernen elektronischen Geräte und Medien, die Landeswährung sowie alle Produkte und Waren ausschließlich Kyrillisch beschriftet wären, so wäre die Problematik wohl recht schnell handhabbar. Das, was in anderen Ländern Europas weitestgehend üblich ist und die Sprachverwendung überschaubar macht, nämlich die Wahl eines alleinigen Schriftsystems, ist aber eben nicht die Realität im heutigen Serbien, so dass es offenbleibt, ob man in Zukunft ein Interesse daran zeigen wird, sich an Kovačevićs Vorschlägen zu orientieren, auch

2 Ibidem, S. 15-18.

3 Ibidem, S. 19.

4 Ibidem, S. 23.

5 Ibidem, S. 4 o. 
wenn sie eine durchaus sinnvolle und vor allem wissenschaftlich fundierte Option darstellen.

Milanka J. Babić reflektiert die Zusammenhänge zwischen dem aktuellen Status der serbischen Sprache in Bosnien und Herzegowina und der Deklaration zur gemeinsamen Sprache. Während bereits das Niveau des Sprachgebrauchs in der Republika Srpska bemängelt wird, so zeige sich in der Föderation ein noch fataleres Bild, nämlich, dass überhaupt kaum ein serbischer Schüler die Kyrilliza lesen und schreiben könne, bevor er sich an der Universität immatrikuliert. ${ }^{6}$ Weiterhin wird auch bei ihr die Deklaration zur gemeinsamen Sprache kritisiert, da sie dazu beitrage, den gesamten serbischen Sprachraum nur noch mehr aufzusplittern, zudem sei die Argumentation ihrer Befürworter in sich widersprüchlich und unlogisch. So würden unterschiedliche polyzentrische Sprachen wie etwa Deutsch, Arabisch oder Englisch als Musterbeispiele angeführt, im Falle des štokavischen Kontinuums würde aber die Bezeichnung als „Serbisch“ vermieden, obwohl es allen voran Vuk Karadžić war, der hier als Initiator für eine vereinheitlichte Schriftsprache eintrat. Es sei daher inkonsequent, dass ein frei wählbares Lingonym postuliert wird. ${ }^{7}$ Daher lautet der Vorwurf, die Proklamation beabsichtige die faktische Abwertung des Status der serbischen Sprache. ${ }^{8}$ Tatsächlich kann dies in folgendem Zusammenhang betrachtet werden: In der Kommunikation mit Sprachträgern einer anderen štokavischen Varietät ist mit hoher Wahrscheinlichkeit zu erwarten, dass die Lateinschrift dominiert oder sogar ausschließlich im Gebrauch ist. Es darf deshalb an dieser Stelle die Überlegung angestellt werden, ob die erwähnte Proklamation letztlich nicht zumindest indirekt gleichermaßen ein Plädoyer gegen die Kyrilliza ist, schließlich wird diese de facto wenn überhaupt - von denjenigen geschrieben, die sich als Serben betrachten.

Jelica R. Stojanović zeigt einen einschneidenden Negativtrend in Montenegro auf, der zu Lasten der serbischen Bevölkerung und ihrer sprachlichen und kulturellen Identität geht. Sie beklagt vor allem den Zuwachs der Maßnahmen zu Gunsten einer montenegrinischen Sprache, die mit dem Ziel implementiert werde, die Alltagssprache als „montenegrinisch“ zu bezeichnen und nicht mehr als „serbisch“.9 Weiterhin sei die kyrillische Schrift bis auf vereinzelte Ausnahmen aus dem öffentlichen Raum verdrängt und Montenegro das erste mehrheitlich orthodoxe Land, welches sie durch die Lateinschrift ersetzte, ${ }^{10}$ was sicher im slavischen Kulturkreis beachtlich ist, in

\footnotetext{
6 Ibidem, S. 51-52.

7 Ibidem, S. 53-54.

8 Ibidem, S. 55.

9 Ibidem, S. 64.

10 Ibidem, S. 65.
} 
anderen Staaten wie etwa Rumänien aber in ähnlicher Form geschah, wenn auch aus anderen Umständen heraus.

Den Schulunterricht in serbischer Sprache im Rahmen des Bildungssystems hinterfragt Veljko Ž. Brborić. Er gibt einen Überblick über die Lage an Grund- und Mittelschulen sowie an der Universität (hier wird neben Serbien auch die Situation in Bosnien und Herzegowina umrissen). ${ }^{11}$ Seiner Ansicht nach hat die dramatische Reduzierung der Unterrichtsstunden an Grundschulen einschneidende Folgen, darüber hinaus müsste ein Konsens zur universitären Lehrvermittlung gefunden werden. ${ }^{12}$

Aleksandra B. Vraneš verdeutlicht in ihrem Artikel die Bedeutung der serbischen Sprache in bibliographischen Darstellungen. Retroperspektivisch lässt sich davon ausgehen, dass sich das serbische Bibliographiewesen für eine Zuordnung von bestimmten Werken an einer Kombination aus unterschiedlichen Faktoren orientiert, welche im Zusammenhang mit nationalen, sprachlichen, historischen und geographischen Gegebenheiten interagieren. Das daraus resultierte kulturelle Gut gelte es zu bewahren. ${ }^{13}$

Abschließend interpretiert Mihailo M. Šćepanović die serbische Sprache als montenegrinische Sprache (сритски језик као ирноіорски). Einleitend gibt er einen knappen Überblick über die serbische Lexikographie, die ihren Lauf mit Vuk Karadžićs Wörterbuch nahm (Рјечник, 1818). ${ }^{14}$ Anschließend wird auch bei ihm die Deklaration zur gemeinsamen Sprache reflektiert, wobei der Autor zunächst auf einige Ungereimtheiten im Text eingeht. Da sämtliche Varietäten des Štokavischen darin als gleichberechtigte Varianten bezeichnet werden, summiert er seine Meinung zu der verwendeten Formulierung folgendermaßen: Друіим речима, срйски језик је варијанта срйской језика, а све то изазива нове йослеgице! Нимало наивне. ${ }^{15}$ Eine willkürliche Sprachbezeichnung sei nicht ohne Weiteres hinzunehmen, und vor allem sei es interessant, dass die Kroaten diesem Dokument weitreichend zustimmten, wo doch gerade in Kroatien das Serbische einen schweren Stand habe, so dass es dort eben nicht gleichgültig sei, wie Individuen ihre Sprache nennen möchten. Stattdessen werden immer wieder Übergriffe auf Serben vor Ort gemeldet, alleine 331 an der Zahl im Jahre 2016. ${ }^{16}$ Das montenegrinische Wörterbuch aus dem Jahre 2016 sei zudem ein Beweis dafür, wie sehr die serbische Sprache in diesem Teil ihres Sprecherareals „montenegrinisiert" werden solle, schließlich habe man in erster Linie daraufgesetzt,

11 Ibidem, S. 83-86.

12 Ibidem, S. 88.

13 Ibidem, S. 93, 101.

14 Ibidem, S. 105-110.

15 Ibidem, S. 113.

16 Ibidem. 
es mit Begriffen aus der Volkssprache anzureichern. ${ }^{17}$ Daher wird das Werk als amateurhafter Versuch eines lexikographischen Ansatzes gesehen, ${ }^{18}$ gleichzeitig ist es jedoch bemerkenswert, dass dieses Wörterbuch in Kyrilliza verfasst wurde und somit in gewisser Weise in Opposition zur Tendenz steht, die zuvor im gleichen Sammelband von Jelica Stojanović abgehandelt wurde.

Welche elementaren Lehren zieht der Leser nun aus der vorliegenden Publikation? Erstens wird die serbische Sprache in ihrer kyrillisch geschriebenen Variante in einigen Bereichen als bedroht angesehen, was unbedingt Ernst genommen werden sollte, denn wie sollen künftige Philologen und Lehrer die grundlegenden Werke der serbischen Sprachgeschichte und Literatur angemessen bearbeiten oder vermitteln, wenn das Kyrillische nicht mehr angewendet wird? Die Frage, welches Schriftbild die Zukunft des Staates vorrangig prägen sollte oder ob nach wie vor eine Biskriptualität erwünscht ist, müssen die Bürger Serbiens letztlich selber entscheiden. $\mathrm{Zu}$ bedenken wäre aber unbedingt, welches Interesse mit der Wahl eines Alphabets einhergeht, was dies im Hinblick auf das nationale Erbe bedeutet und ob man in Bezug auf Kulturvermittlung verantwortungsbewusst handeln wird. In Staaten wie etwa der Türkei oder Rumänien haben Umstellungen auf die Lateinschrift längst stattgefunden, allerdings ist ein Nebeneffekt, dass eine durchschnittliche Schulausbildung heutzutage nicht ausreichend ist, um beispielsweise originale historische Dokumente zu studieren. Der gravierende Unterschied in Serbien ist jedoch folgender: Während das arabische Schriftbild im osmanischen Türkisch oder das kyrillische im Rumänischen zur Abbildung des jeweiligen Lautsystems eher ungünstig waren, so ist im Gegensatz dazu die Kyrilliza das am besten geeignete Instrument zur Wiedergabe des Serbischen in Schriftform. Nicht nur, dass das serbisch-kyrillische Alphabet eigens für die Bedürfnisse der Sprecher entwickelt wurde, sondern es ist gleichermaßen die am ehesten dem ökonomischen Prinzip entsprechende Variante, die die Schriftsprache zur Verfügung stellt, da hier tatsächlich ein Graphem mit einem Phonem korrespondiert, was die Latinica eben nicht leisten kann (vgl. die Fusion von $\pi$ und $b$ bzw. $\mu$ und $b$ zu den Monographen $J b$ und $r$, aber $l j$ und $n j$ de facto als optische Bigraphen, selbst wenn man sie nicht als solche klassifiziert).

Zweitens wird das Spannungsfeld samt der komplexen sprachpolitischen Situation aufgezeigt, auf die man im gesamten štokavischen Sprachgebiet vorbereitet sein muss. Die Autoren dokumentieren, dass es aus historischen und geographischen Gründen eine heikle Angelegenheit ist, Vereinheitlichungen wie etwa inoffizielle Deklarationen in die Welt zu setzen, die möglicherweise einen gut gemeinten Kernansatz verfolgen, allerdings auch in ihren Formulierungen und somit terminologisch anfechtbar sind.

17 Ibidem, S. 116, 119.

18 Ibidem, S. 130. 
Die serbische Reaktion darauf in wissenschaftlichen Kreisen ist absehbar, man zeigt kein Verständnis dafür, warum das Fundament einer gemeinsamen Schriftsprache, an dem die serbische Seite entscheidend beteiligt war, nicht mit einem entsprechenden Attribut versehen werden soll. Im Ergebnis wäre nach Ansicht der Autoren alles andere als das Lingonym „Serbisch“ für die postulierte polyzentrische Varietät unlogisch.

Es lässt sich drittens festhalten, dass es sich um eine wichtige Publikation handelt, die Einblicke in den štokavischen Sprachraum aus serbischer Perspektive gibt und argumentativ darlegt, warum bestimmte Affinitäten in der gesamten Region nach wie vor eine zentrale Rolle spielen. Die Kyrilliza und ihre kulturhistorische Bedeutung werden angesprochen und es bleibt unbedingt zu wünschen, dass die hier präsentierten Einzelbeiträge auch als Denkanstoß interpretiert werden und Gehör finden, in erster Linie in Serbien selbst. Schließlich liegt es in den Händen der Politik, regulierend zu wirken und dabei abzuwiegen, welcher Weg tatsächlich im Interesse der Einwohner des Landes und der nächsten Generation ist und welche konkreten Maßnahmen ergriffen werden sollten, um dem so wichtigen Ziel des Sprachschutzes ein Stück näher zu kommen. Ein wichtiger Schritt war daher sicher die Декларација о очуваюу срйской језика и културе von 2018, aber wird sie wirklich einen Durchbruch auf allen Ebenen markieren können? Jedenfalls sollte die eindeutige Meinung zu dem Thema aus akademischen Kreisen auch in Zukunft berücksichtigt werden, denn sie könnte als wichtige Richtschnur für weitere Entscheidungen dienen.

Martin Henzelmann

\section{Bibliografie:}

KUSTURICA, E. (ed.): Srpski jezik i ćirilica danas: zbornik radova. Andrićgrad: Andrićev institut, 2017.

\section{A Unique Multiperspective and Multidisciplinary Insight into the Issue of Global Communication}

ЗЕРНЕЦЬКА, О.: Глобальна комунікація. Київ: Наукова думка, 2017. 350 р.

About the author: Olga Zernetska is Professor, Dr. Hab. in Communication and Political Studies, head of the Department of Global and Civilization Problems of the Institute of World History of the National Academy of Sciences of Ukraine; the author of 5 individual monographs, 30 collective monographs and 300 scientific articles 